\title{
ErbB3 expression predicts sensitivity to elisidepsin treatment: In vitro synergism with cisplatin, paclitaxel and gemcitabine in lung, breast and colon cancer cell lines
}

\author{
CRISTINA TEIXIDÓ ${ }^{1}$, ELISABET ARGUELAGUET ${ }^{1}$, BERTA PONS ${ }^{1}$, MIGUEL ARACIL $^{2}$, JOSE JIMENO ${ }^{2,3}$, \\ ROSA SOMOZA $^{1}$, ROSO MARÉS ${ }^{1}$, SANTIAGO RAMÓN Y CAJAL ${ }^{1}$ and JAVIER HERNÁNDEZ-LOSA ${ }^{1}$ \\ ${ }^{1}$ Department of Pathology, Hospital University Vall d'Hebron, 08035 Barcelona; \\ ${ }^{2}$ Pharmamar, 28770 Colmenar Viejo, Madrid, Spain
}

Received November 17, 2011; Accepted January 23, 2012

DOI: $10.3892 /$ ijo.2012.1425

\begin{abstract}
Irvalec ${ }^{\circledR}$ (elisidepsin trifluoroacetate, PM02734) is a novel marine-derived cyclic peptide belonging to the Kahaladide family of compounds, currently in clinical trials with preliminary evidence of antitumor activity. Previous studies have shown a correlation between elisidepsin sensitivity and expression of the ErbB3 receptor in a panel of NSCLC cell lines. We have studied the effect of elisidepsin on the ErbB3 pathway, characterizing the expression of all members of the ErbB (HER) family of receptors and their main downstream signaling effectors, such as Akt and MAPK. Interestingly, we observed a downregulation of ErbB3 upon elisidepsin treatment that correlates with a reduction in the Akt phosphorylation levels in the most sensitive cell lines, whereas ErbB3 levels are not affected in the less sensitive ones. Also, we observed that the basal levels of ErbB3 protein expression show a significant correlation with cell viability response against elisidepsin treatment in 14 different cell lines. Furthermore, we analyzed the combination of elisidepsin with different chemotherapeutics agents, such as cisplatin, paclitaxel and gemcitabine, in a panel of different breast (MDA-MB-435, MDA-MB-231 and MCF7), lung (HOP62, DV90 and A549) and colorectal cancer cell lines (DLD1 and HT29). IC $_{50}$ values for the different drugs were tested. We observed a synergistic effect in all cell lines tested with any chemotherapeutic agent. More importantly, the two in vitro elisidepsin-resistant cell lines (MDA-MB-231 and HOP62) presented a synergistic effect in combination with cisplatin and paclitaxel, respectively. These results provide a
\end{abstract}

Correspondence to: Dr Javier Hernández-Losa, Department of Pathology, Vall d'Hebron University Hospital, Pg. Vall d'Hebron 119-129, 08035-Barcelona, Spain

E-mail: jahernan@vhebron.net

Present address: ${ }^{3}$ Pangaea Biotech, Medical Oncology Service and Laboratory, USP Instituto Universitario Dexeus, Sabino Arana 5-19, 08028 Barcelona, Spain

Key words: elisidepsin, ErbB3, cisplatin, gemcitabine, paclitaxel rationale for further development of these combinations in an ongoing clinical trial.

\section{Introduction}

Nowadays, the prognosis of most advanced carcinomas remains poorly understood and the search of new drugs is crucial. Recent clinical data obtained with new EGFR inhibitors in lung tumors harboring EGFR mutations are promising but the complex genetic background of most of these tumors and the redundancy of genetic drivers indicates that combination with other antitumor agents is needed. In this regard, the search of chemical compounds obtained from marine organisms could be an interesting new approach. Several compounds were found in some previous screening with a high antitumor activity such as Yondelis ${ }^{\circledR}$ in sarcomas and more recently in ovarian cancer (1).

Irvalec $^{\circledR}$ (elisidepsin trifluoroacetate, PM02734), a novel synthetic marine-derived antitumor agent belonging to the Kahalalide family of peptides originally isolated from the Hawaiian marine mollusk Elysia rufescens (2), is currently undergoing phase II clinical trials.

Elisidepsin has shown a potent in vitro cytotoxic activity toward several epithelial cell lines (3) and this activity is markedly higher in tumorigenic vs. normal cell lines $(4,5)$. In addition, elisidepsin shows statistically significant in vivo antitumor activity in several human cancer cell lines xenografted into mice. Based on these observations, and in view of its acceptable low clinical toxicity profile, elisidepsin has been selected for clinical development (6). In phase I trials Irvalec was shown to be safe, well tolerated and with evidence of activity in patients with solid tumors (7-9).

In vitro treatment of tumor cells with elisidepsin induces necrotic cell death by inducing rapid and severe membrane damage, a process that appears to involve 2-hydroxy fatty acids located at the cell membrane (10).

Interestingly, previous in vitro studies with the natural parent compound Kahalalide F (KF) have shown that KF inhibits the tyrosine kinase activity of HER $2 /$ neu, blocks EGFR and inhibits the expression of TGF- $\alpha$ (11). The sensitivity to KF in a panel of tumor cell lines, including non-small 
cell lung cancer (NSCLC), breast, ovarian and hepatic carcinomas was found to correlate with ErbB3 protein expression levels, whereas no correlation was observed with the expression levels of the other family members (12). KF induces a downregulation of this receptor, subsequently reducing the levels of phospho-Akt, resulting in a significant reduction of the cellular survival rate.

In vitro and in vivo synergism has been described when combining elisidepsin with a specific small tyrosine kinase inhibitor of EGFR (erlotinib) in NSCLC (13). Because human carcinomas harbor multiple genetic alterations, the combination of different antitumor agents is essential in most cases. Classical antitumor agents such cisplatin (CDDP), gemcitabine and paclitaxel (TAX) are frequently used in carcinomas with unpredictable results. The combination with synergistic drugs could be a relevant approach to increase the rate of tumor responses.

CDDP is a typical DNA-damaging agent with the ability to induce crosslinking between inter and intra DNA strands (14). CDDP is also known for its ability to induce apoptosis, although other mechanisms have been reported to induce cell death (15). CDDP therapy is used in several types of tumors such as NSCLC, testicular and ovarian cancer. TAX belongs to a family of drugs that, through the blocking of microtubule formation, interfere with the normal progression of the cell cycle. The drug has therefore been successfully used in the treatment of breast, lung, melanoma and ovary tumors $(16,17)$. Gemcitabine is an anticancer nucleoside that is an analog of deoxycytidine. This compound has been widely used in pancreatic and metastatic breast cancer. These chemotherapeutic agents have shown a limited effect, and in recent years, a huge number of combined studies with other compounds have been proposed (18-20).

In this study we sought to characterize the cytotoxic effect of elisidepsin in a panel of human lung, breast and colon carcinoma cell lines, and subsequently a combination of elisidepsin with CDDP, TAX and gemcitabine. Here we show that elisidepsin exposure induced downregulation of ErbB3 protein expression, thus inhibiting the PI3K-Akt signaling pathway in most cell lines, but only partially affecting the MAPK pathway, indicating that the drug severely affects the ErbB3 signaling pathway. We provide further evidence that in vitro sensitivity to elisidepsin correlates with ErbB3 protein expression. Cell lines with high levels of ErbB3 receptor were found to be the most sensitive to elisidepsin.

Finally, the combination of elisidepsin with CDDP, TAX and gemcitabine showed a synergistic effect in almost all cell lines tested, regardless of their genetic background or their sensitivity to each drug alone. Our observations suggest a clinical use of elisidepsin, and its combination with CDDP, TAX or gemcitabine, may improve the efficiency in the chemotherapy currently used in different types of cancer.

\section{Materials and methods}

Chemicals. Elisidepsin was obtained from PharmaMar (Madrid, Spain) as a dry powder to be reconstituted with dimethyl sulfoxide (DMSO, Sigma Chemical Corp.)/ethanol (1:1) as a $1 \mathrm{mM}$ stock solution, and kept in aliquots at $-20^{\circ} \mathrm{C}$. CDDP, TAX or gemcitabine were obtained from the Vall
d'Hebron University Hospital (Barcelona, Spain). Drug dilutions were freshly prepared before each experiment.

Cells and cell culture. Cell lines were obtained from the American Type Culture Collection, except from DV90 cell line, purchased from the Deutsche Sammlung von Mikroorganismen und Zellkulturen GmbH. The HCT116 p53 ${ }^{-/}$was kindly provided by Dr Francisco Real (Centro Nacional de Investigaciones Oncológicas, CNIO, Madrid). The following cell lines were maintained in RPMI-1640 with $4 \mathrm{mM}$ L-glutamine: DV90, HOP62 (lung carcinoma), MDA-MB-231, MCF-7, SKBR3, MDA-MB-435 (breast carcinoma) and AsPC-1, BxPC-3 (pancreas carcinoma). The following were maintained in Dulbecco's modified Eagle's medium (DMEM) with $4 \mathrm{mM}$ L-glutamine and $4.5 \mathrm{~g} / \mathrm{l}$ of glucose: DLD1, HT29, HCT116 p53 $3^{+/}$, HCT116 p53 ${ }^{-/}$(colon carcinoma), MDA-MB468 (breast carcinoma), PANC-1, MIAPaCa-2 (pancreas carcinoma) and the human embryonic kidney 293T (HEK 293T) cancer cell line. A549 (lung carcinoma) was maintained in Ham's F-12 medium supplemented with $1 \mathrm{mM}$ L-glutamine. Finally, DMEM:Ham's F12 (1:1 mixture) supplemented with $1 \mathrm{mM}$ L-glutamine was used to maintain BT-474 (breast carcinoma). All cell lines were supplemented with $10 \%$ fetal bovine serum, $100 \mathrm{U} / \mathrm{ml}$ penicillin, $100 \mu \mathrm{g} / \mathrm{ml}$ streptomycin and $10 \mathrm{mM}$ HEPES and were cultured in a $37^{\circ} \mathrm{C}$ humidified atmosphere containing $95 \%$ air and $5 \% \mathrm{CO}_{2}$.

Cell growth assay. Cells were plated overnight at a density of 50,000 cells/well in 24-well plates in $1 \mathrm{ml}$ of medium. At least 3 wells were used for each condition. Cell lines were treated with various concentrations of elisidepsin, CDDP, TAX or gemcitabine for $72 \mathrm{~h}$ as single agents. Cell viability was measured by a crystal violet assay. Briefly, after each treatment, cells were fixed in $1 \%$ glutaraldehyde for $20 \mathrm{~min}$, washed twice in PBS $1 \mathrm{X}$, stained with $0.1 \%$ crystal violet for $30 \mathrm{~min}$ and then washed with abundant deionized water. Colorant was recovered with $5 \%$ acetic acid and optical density was measured at $590 \mathrm{~nm}$ using an ELISA plate reader.

Analysis of combined drug effects. Cells were plated in 24-well plates as described above. After overnight incubation at $37^{\circ} \mathrm{C}$, the attached cells were treated for $72 \mathrm{~h}$ at a fixed ratio of doses that corresponded to $0.125,0.25,0.5,1$ and 2 times the individual $\mathrm{IC}_{50}$ values of elisidepsin in combination with CDDP, TAX and gemcitabine. Cell survival fractions were determined by crystal violet assay and the combination indexes (CI) were analyzed by the median effect method of Chou and Talalay by using CalcuSyn software (version 2.1, Biosoft, Cambridge, UK) (21). CI $<1, C I=1, C I>1$ indicate synergism, additive effect and antagonism, respectively. The study was repeated three independent times and representative data are shown.

Western blot analysis. Just prior to use, cultured cells for western blotting were scraped in lysis buffer containing $20 \mathrm{mM}$ Tris $\mathrm{HCl}$ (pH 8.0), $137 \mathrm{mM} \mathrm{NaCl}, 2$ mM EDTA, 10\% glicerol, 1\% NP-40, 0.1 M sodium pyrophosphate, $20 \mathrm{mM}$ $\beta$-glycerophosphate, $1 \mathrm{mM}$ DTT, $20 \mathrm{mM} \mathrm{NaF}, 2 \mathrm{mM} \mathrm{Na} \mathrm{VO}_{4}$, $1 \mathrm{mM}$ phenylmethylsulfonyl fluoride, $1 \mu \mathrm{g} / \mathrm{ml}$ leupeptin and $1 \mu \mathrm{g} / \mathrm{ml}$ aprotinin. Lysates were centrifuged and supernatants were collected for protein concentration determination by 
the Bradford protein assay reagent (Bio-Rad) method. Equal amounts of protein were separated by $8 \%$ sodium dodecyl sulfate (SDS) polyacrylamide gel electrophoresis (PAGE) gels, electrophoresed at $100 \mathrm{~V}$ and electroblotted onto polyvinylidene difluoride membranes (Millipore) at $0.4 \mathrm{~A}$ at room temperature. Blots were blocked in 5\% dried milk solution for $1 \mathrm{~h}$ at room temperature and probed overnight with antibodies. After blocking, membranes were probed with primary antibodies against ErbB1 (F4, Sigma), ErbB2 (CB11, BioGenex), ErbB3 (2F12, NeoMarkers), p-ErbB3 (21D3), ErbB4 (111B2), p-Akt (587F11), Akt (\#9272), p-MAPK (\#9101), $\beta$-actin (\#A5060) (Cell Signaling) and MAPK (C-14, Santa Cruz Biotechnology), upon treatment with $1 \mu \mathrm{M}$ elisidepsin for $4 \mathrm{~h}$. After incubation with horseradish peroxidase-conjugated secondary antibodies, antigen-antibody complexes were visualized using enhanced chemiluminescence (Amersham Biosciences). Western blot analyses were repeated in independent conditions at least twice; representative blots are shown.

Immunoprecipitation. Cells were treated and collected in lysis buffer. Extracts were precleared and the soluble fraction was incubated with anti-ErbB3 $(1 \mathrm{mg} / \mathrm{sample})$ overnight at $4^{\circ} \mathrm{C}$. The following day, extracts were incubated for $45 \mathrm{~min}$ in the presence of protein G Sepharose 4 Fast Flow (17-0618-01, Amersham Pharma-Biotech), centrifuged at 12,000 x g for $20 \mathrm{sec}$ and then washed three times with $1 \mathrm{ml}$ in the same lysis buffer. The pellet was suspended in $30 \mu \mathrm{l}$ sample reducing buffer (1\% SDS, $100 \mathrm{mM}$ DTT, $50 \mathrm{mM}$ Tris, $\mathrm{pH}$ 7.5). Then immunocomplexes were resuspended in loading buffer and loaded onto 8\% SDS-PAGE gels. Quantification of autoradiograms was performed by using Image $\mathbf{J}$ software (version 1.41o, National Institutes of Health, Bethesda, MD), normalized to the intensity of $\beta$-actin in each sample, and expressed in arbitrary densitometric units.

\section{Results}

Elisidepsin downregulates ErbB3 protein level. Previous studies have reported a selective downregulation of ErbB3 after cell exposure to the natural compound KF in a cell line expressing high levels of this receptor SKBR3. We sought to determine if elisidepsin treatment could similarly affect the expression of other ErbB receptors. To this end, we did a time course of 2, 4 and $6 \mathrm{~h}$ treatment with $1 \mu \mathrm{M}$ of elisidepsin, and western blot analysis to seek if the treatment induces the downregulation of the ErbB family proteins in MCF-7 breast cancer cell line, which expresses moderate ErbB3 protein levels.

Protein expression levels of all members of the ErbB family were analyzed and all were found to be downregulated after $6 \mathrm{~h}$ of treatment with elisidepsin (Fig. 1). Unlike other ErbB receptors, the downregulation of the expression of ErbB3 protein level was seen as early as $2 \mathrm{~h}$. Interestingly, in the case of the ErbB4 protein levels, we observed an initial upregulation at 2 and $4 \mathrm{~h}$ post-treatment. This result clearly indicates that ErbB3 is the ErbB receptor most sensitive to treatment with elisidepsin in MCF-7 cells.

ErbB3, p-Akt and $p$-MAPK are downregulated upon elisidepsin treatment. Since downregulation of ErbB protein

\section{Elisidepsin $1 \mu \mathrm{M}$}

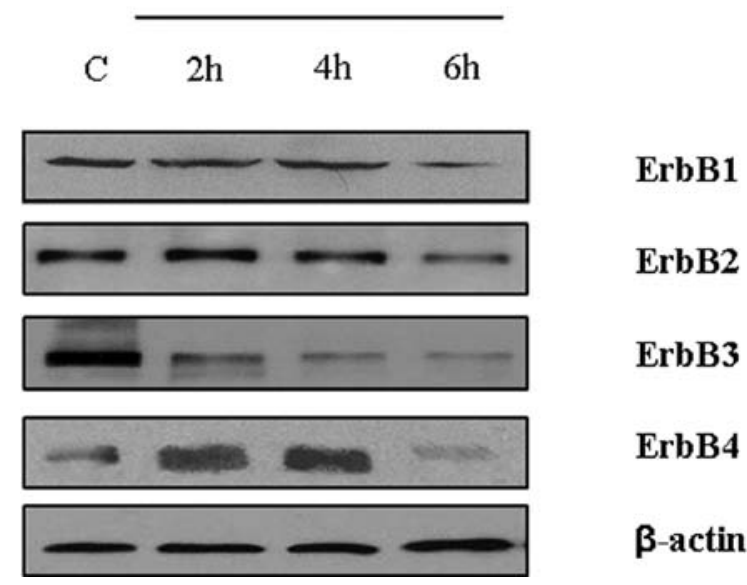

Figure 1. Downregulation of the expression of ErbB family proteins upon elisidepsin treatment. MCF-7 cells were seeded at $70 \%$ confluence, and after $24 \mathrm{~h}$ cells were treated at 2, 4 and $6 \mathrm{~h}$ with $1 \mu \mathrm{M}$ elisidepsin. After treatment, cells were lysed and proteins were extracted and quantified by Bradford assay. Protein $(50 \mu \mathrm{g})$ was loaded in SDS-PAGE gels. The four ErbB receptors were detected by western blot assays using corresponding antibodies. The membranes were stripped and reprobed with anti- $\beta$-actin to verify equal protein loading.

expression was observed in MCF-7 cells upon elisidepsin treatment, we sought to determine if this compound also affected ErbB3 expression in a panel of human tumor cell lines with variable expression levels of this receptor, namely lung (A549, DV90 and HOP62), breast (MDA-MB-435, MDA-MB-231 and MCF-7) and colon (DLD1 and HT29) cancer cell lines.

Cells were treated with $1 \mu \mathrm{M}$ elisidepsin for $4 \mathrm{~h}$ and then lysed. ErbB3 receptor levels were downregulated in the majority of cell lines analyzed after treatment with $1 \mu \mathrm{M}$ elisidepsin. Only two (MDA-MB-231 and HOP-62) out of eight cell lines tested maintained their ErbB3 expression levels after elisidepsin treatment.

Those differences in ErbB3 receptor levels in the analyzed cell lines prompted us to study the downstream signaling routes that link this receptor to proliferative responses, Akt and MAPK. Western blot analysis with antibodies that recognized activated forms of Akt indicated that the resting levels of p-Akt were lower or had disappeared more notably in the cells that had a downregulation of ErbB3 after elisidepsin treatment than in the cells that had not (Fig. 2A).

We also investigated the phosphorylation of MAPK. In contrast to p-Akt results, p-MAPK levels were not downregulated in most of the cell lines. MAPK phosphorylation was upregulated in HOP62 and MDA-MB-435 cell lines, and downregulated in A549 and DV90 lung cancer cell lines, MCF-7 breast cancer cell line and DLD1 colon cancer cell line. MDA-MB-231 and HT29 cell lines maintained the same amount of p-MAPK protein after treatment with the drug.

In contrast, total amounts of Akt and MAPK are not affected by elisidepsin, except for the DLD1 colon cancer cell line that exhibited a decrease in Akt protein expression levels. We also analyzed $\beta$-actin state to verify an equal amount of protein in each well. 
A

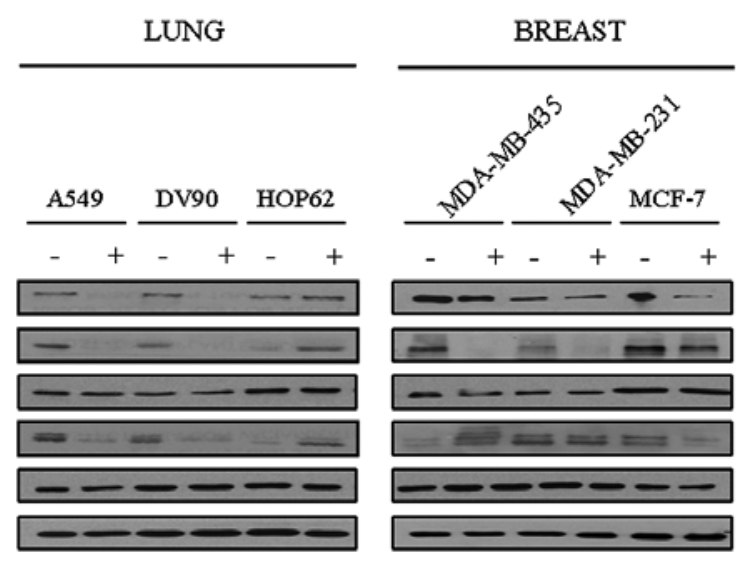

B

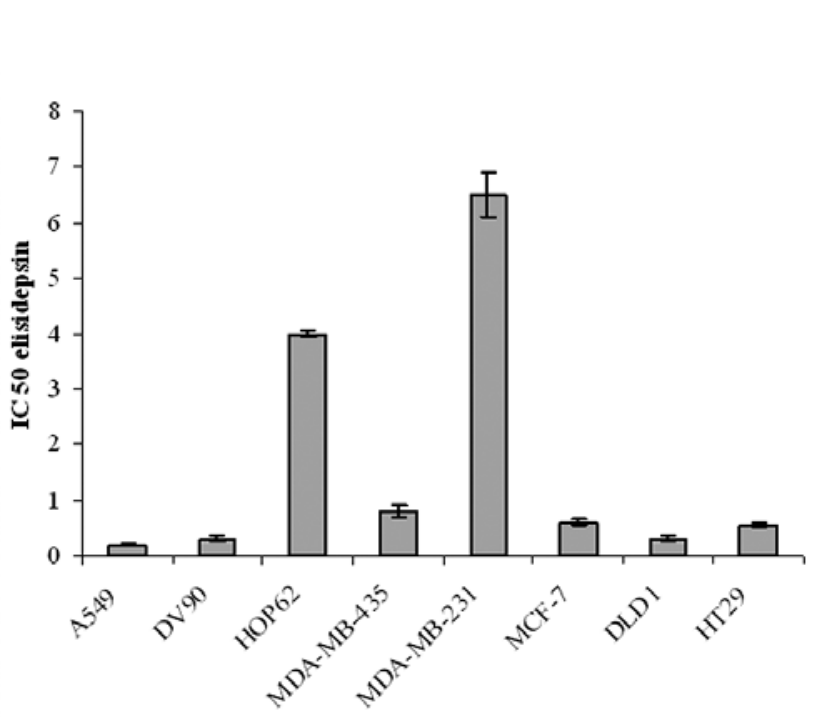

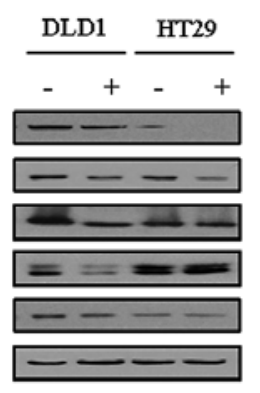

C

\section{Elisidepsin 1 $1 \mu \mathrm{M}$ \\ ErbB3 \\ $\mathrm{p}-\mathrm{AKT}$ \\ AKT \\ p-MAPK \\ MAPK \\ $\beta$-actin}

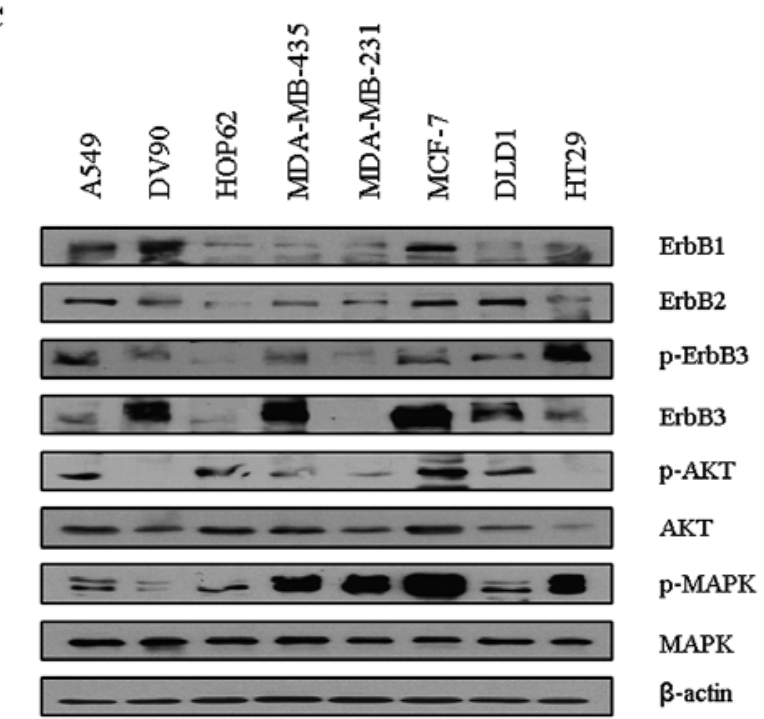

Figure 2. Effect of elisidepsin treatment on ErbB signaling pathways. (A) All cell lines were seeded at $70 \%$ of confluence in 100 -mm cell culture dishes, and $18 \mathrm{~h}$ later, were treated with $1 \mu \mathrm{M}$ of elisidepsin for $4 \mathrm{~h}$. After treatment, cells were lysed, proteins were extracted and western blot analysis performed with $50 \mu \mathrm{g}$ of protein, for each sample. In the control samples, the same amount of the dissolved product (DMSO/ethanol) without elisidepsin was added. Membranes were stripped and reprobed with anti- $\beta$-actin and these were used as an internal control. (B) Representation of cell viability upon 72-h treatment with different concentrations of elisidepsin in a panel of 8 different cell lines. Bars indicate $\mathrm{IC}_{50}$ values $( \pm \mathrm{SD})$ for 3 independent experiments per cell line. $(\mathrm{C}) \mathrm{A}$ total amount of $50 \mu \mathrm{g}$ of protein extracts from 8 different cell lines were loaded in SDS-PAGE gels and western blot analyses were performed against different antibodies regarding HER family, also p-Akt and p-MPAK activation. $\beta$-actin was used as an internal control to verify equal protein loading.

These results indicate that elisidepsin affected ErbB3 protein levels, the downstream pathway PI3K-Akt, and in some cases also the MAPK route in cell lines derived from different human tumor types.

ErbB3 expression levels correlate with elisidepsin cell sensitivity. We performed cell viability assays in a panel of cell lines to analyze if there was a correlation between the downregulation of ErbB3 protein expression and cell sensitivity to elisidepsin. Cells were treated with increasing concentrations of the compound for $72 \mathrm{~h}$. $\mathrm{IC}_{50}$ values for elisidepsin, as measured by crystal violet assays using a spectrophotometer, ranged from 0.2 to $6.5 \mu \mathrm{M}$ within the panel of cell lines (Fig. 2B).

The cells that have an $\mathrm{IC}_{50}$ value $\leq 1 \mu \mathrm{M}$ were considered sensitive, while the rest were considered less sensitive to the drug. HOP62 and MDA-MB-231 cell lines were the only cell lines that had an $\mathrm{IC}_{50}$ value $>1 \mu \mathrm{M}$ ( 4 and $6.5 \mu \mathrm{M}$, respectively). The other cell lines were catalogued as sensitive to the drug ( $\mathrm{IC}_{50}$ value from 0.2 to $0.6 \mu \mathrm{M}$ ) and, as we described above, all of them presented downregulation of the ErbB3 receptor. We did not observe any relationship between HER1 and HER2 expression levels and elisidepsin sensitivity (Fig. 2C).

To analyze if there is a correlation between ErbB3 expression levels and elisidepsin sensitivity we performed cell viability assays in a larger panel of cell lines. We chose 14 human cell lines from different types of cancer (comprising pancreas, breast, lung, colon and kidney cell lines). $\mathrm{IC}_{50}$ values for elisidepsin ranged from 0.075 to $14 \mu \mathrm{M}$ within the panel of cell lines (Fig. 3A).

In order to evaluate the ErbB3 protein expression levels and correlate them with the sensitivity of the cell lines to elisidepsin, we performed different analysis based on western blot analysis (data not shown) and immunoprecipitation in 14 cell lines (Fig. 3B). Cell lines that were less sensitive to elisidepsin had lower or no ErbB3 in comparison with the sensitive cell lines which expressed higher levels, the results being statistically significant, $\mathrm{p}=0.015$ in a Wilcoxon test (Fig. 3C). In summary, we observed a marked correlation between ErbB3 


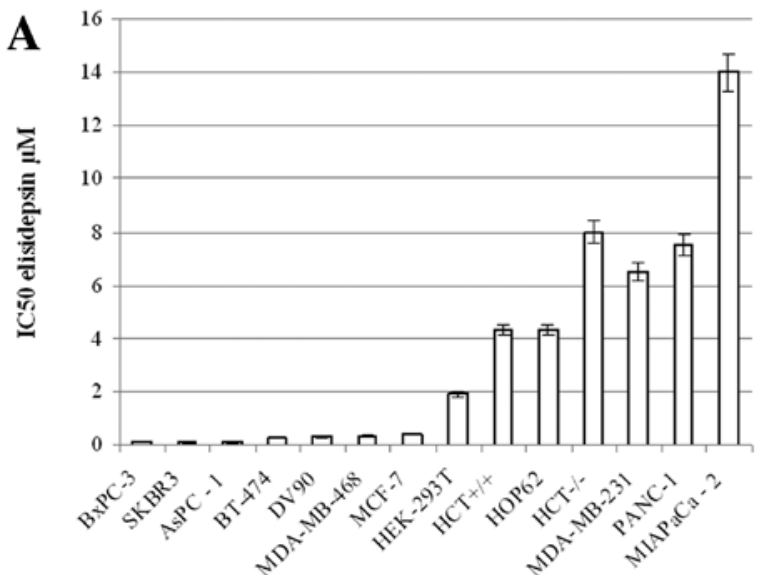

B

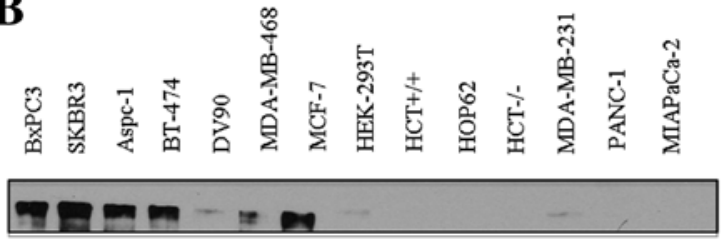

ErbB3

C

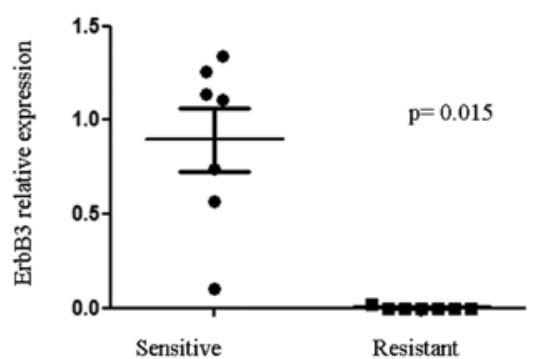

Figure 3. ErbB3 expression correlates with elisidepsin cell sensitivity. (A) Cell viability assay upon 72-h treatment with different concentrations of elisidepsin in 14 human cell lines. Bars indicate $\mathrm{IC}_{50}$ values $( \pm \mathrm{SD})$ for 3 independent experiments per cell line. (B) Total ErbB3 protein expression in different cell extracts was detected by western blot analysis after immunoprecipitation with $1 \mu \mathrm{g}$ of ErbB3 antibody. (C) Levels of ErbB3 protein were quantified from western blot analysis (data not shown) by densitometry. The graph represents the ErbB3 relative expression in cell lines, classified as more sensitive $\left(\mathrm{IC}_{50}<1 \mu \mathrm{M}\right)$ and less sensitive $\left(\mathrm{IC}_{50}>1 \mu \mathrm{M}\right)$ to elisidepsin. We obtained a statistical significance $\mathrm{p}=0.015$ with the Wilcoxon analysis test. protein expression and cell sensitivity to elisidepsin in a panel of 14 cell lines.

Combinational studies of elisidepsin with CDDP, TAX or gemcitabine. After seeing a correlation between the sensitivity and downregulation of ErbB3 protein after the treatment of elisidepsin we defined the sensitivity to the first panel of 8 cell lines studied performing cell viability assays with different compounds used routinely in conventional chemotherapeutic treatments, namely CDDP, TAX and gemcitabine. The conditions of these experiments were the same as the cell viability assays for elisidepsin. The values of the different compounds ranged from 2.64 to $24.75 \mu \mathrm{M}$ of CDDP, from 7 to $40 \mathrm{mM}$ of TAX and from 0.004 to $2 \mu \mathrm{M}$ of gemcitabine, data not shown.

DLD1 cells were the most resistant to CDDP and the MDA-MB-435 cell line the most sensitive one. Regarding the TAX treatment also the DLD1 cell line together with HOP62 cell line were the more resistant to it and the A549 cells the most sensitive. For the gemcitabine treatment, DLD1 cell line was again the most resistant and the A549 cells the most sensitive. For all three compounds the DLD1 cell line was the most resistant, in contrast to the elisidepsin treatment, which was one of the most sensitive $(0.3 \mu \mathrm{M})$. Next we wanted to determine the potential synergism of the combination of elisidepsin with other antitumor agents such as CDDP, TAX and gemcitabine, performing different combinational drugs assays.

The combination of elisidepsin and CDDP was synergistic in all cell lines except in the HT29 colon adenocarcinoma cell line (Table I). Several cell lines present synergistic effect with high doses such as DV90, HOP62, MCF-7, whereas others cell lines have the same effect a low doses of each drug such as MDA-MB-231 (Fig. 4). However, in the breast cancer cell line MDA-MB-435 we observed synergism at x0.25 and $\mathrm{x} 2$ times the individual $\mathrm{IC}_{50}$ values for the compounds. DLD1 cell line presented synergism with elisidepsin and CDDP at a broad range of doses of both drugs.

In contrast, the combination of elisidepsin and TAX showed synergism in all cell lines (Table II). Several cell lines, exhibit the same tendency of synergism with TAX and CDDP such as MDA-MB-435 and DLD1. Whereas other cell lines such as

Table I. In vitro combination of elisidepsin and cisplatin.

\begin{tabular}{|c|c|c|c|c|c|c|}
\hline Cell line & Origin & $\mathrm{CI}$ (at $0.125 \times \mathrm{IC}_{50}$ ) & $\mathrm{CI}$ (at $\left.0.25 \times \mathrm{IC}_{50}\right)$ & $\mathrm{CI}\left(\right.$ at $\left.0.5 \times \mathrm{IC}_{50}\right)$ & $\mathrm{CI}\left(\right.$ at $\left.1 \times \mathrm{IC}_{50}\right)$ & $\mathrm{CI}\left(\right.$ at $\left.2 \mathrm{xIC}_{50}\right)$ \\
\hline A549 & Lung & 4.89 & 1.14 & 1.06 & 0.75 & 1.21 \\
\hline DV-90 & Lung & 1.32 & 1.03 & 1.4 & 0.48 & 0.88 \\
\hline HOP-62 & Lung & 38.88 & 2.12 & 3.64 & 0.85 & 0.75 \\
\hline MDA-MB-435 & Breast & 1.42 & 0.72 & 1.28 & 2.28 & 0.66 \\
\hline MDA-MB-231 & Breast & 0.72 & 0.6 & 0.66 & 0.91 & 1.6 \\
\hline MCF-7 & Breast & 1.82 & 1.39 & 1.32 & 3.45 & 0.72 \\
\hline DLD-1 & Colon & 0.63 & 0.79 & 1.1 & 0.6 & 0.82 \\
\hline НТ-29 & Colon & 1.76 & 1.22 & 1.28 & 1.97 & 1.1 \\
\hline
\end{tabular}

$\mathrm{CI}$, combination indexes. $\mathrm{CI}<1, \mathrm{CI}=1, \mathrm{CI}>1$ indicate synergism, additive effect and antagonism, respectively. Bold text indicates a synergistic effect when the two different drugs were combined $(\mathrm{CI}<1)$. 
Table II. In vitro combination of elisidepsin and paclitaxel.

\begin{tabular}{|c|c|c|c|c|c|c|}
\hline Cell line & Origin & $\mathrm{CI}$ (at $0.125 \mathrm{xIC}_{50}$ ) & $\mathrm{CI}\left(\right.$ at $\left.0.25 \times \mathrm{IC}_{50}\right)$ & $\mathrm{CI}\left(\right.$ at $\left.0.5 \times \mathrm{IC}_{50}\right)$ & $\mathrm{CI}\left(\right.$ at $\left.1 \times \mathrm{IC}_{50}\right)$ & $\mathrm{CI}\left(\right.$ at $\left.2 \mathrm{xIC}_{50}\right)$ \\
\hline A549 & Lung & 0.78 & 0.81 & 0.93 & 1.35 & 1.65 \\
\hline DV-90 & Lung & 0.73 & 0.85 & 0.92 & 1.13 & 1.73 \\
\hline HOP-62 & Lung & 0.41 & 0.39 & 0.63 & 0.86 & 1.03 \\
\hline MDA-MB-435 & Breast & 0.73 & 0.72 & 1.35 & 2.36 & 0.78 \\
\hline MDA-MB-231 & Breast & 15.14 & 0.92 & 1.17 & 2.27 & 2.81 \\
\hline MCF-7 & Breast & 0.81 & 1.28 & 1.39 & 1.05 & 1.14 \\
\hline DLD-1 & Colon & 0.55 & 0.75 & 1.42 & 2.54 & 0.89 \\
\hline HT-29 & Colon & 0.94 & 1.11 & 1.33 & 0.93 & 1.18 \\
\hline
\end{tabular}

CI, combination indexes. $\mathrm{CI}<1, \mathrm{CI}=1, \mathrm{CI}>1$ indicate synergism, additive effect and antagonism, respectively.

A

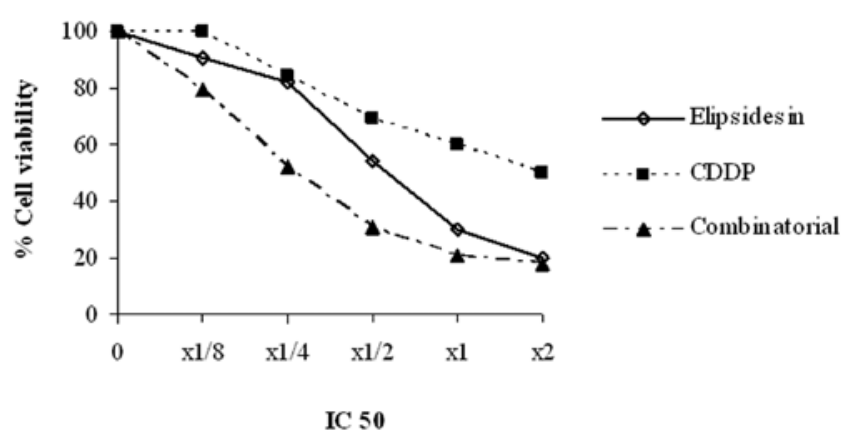

B

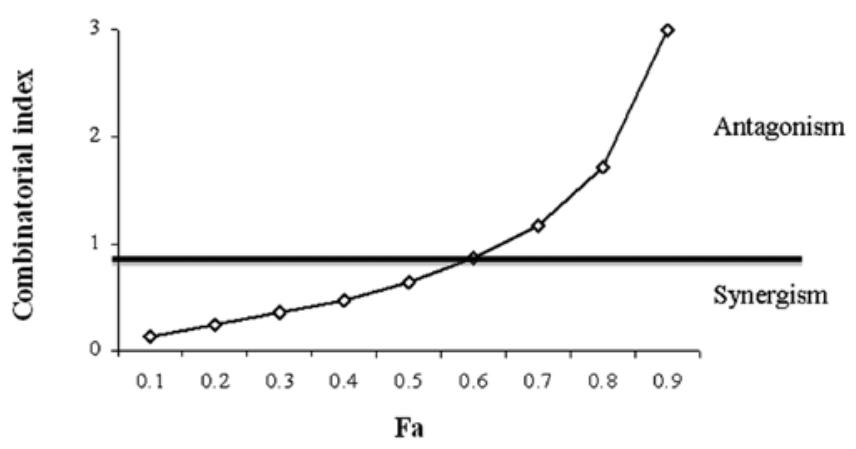

Figure 4. Combination of elisidepsin with CDDP, TAX and gemcitabine. (A) MDA-MB-231 cells were plated overnight at a density of 50,000 cells/well in 24-well plates in $1 \mathrm{ml}$ of medium, and then treated for $72 \mathrm{~h}$ at a fixed ratio of doses that corresponded to $0.125,0.25,0.5,1$ and 2 times the individual $\mathrm{IC}_{50}$ values for each drug alone. Cell viability was measured by a crystal violet assay for optical density using a spectrophotometer. (B) Isobologram representation of $\mathrm{CI}$ (combination index) vs. fractional effect analyzed by software CalcuSyn in MDA-MB-231 cancer cell line. CI $<1$ and CI $>1$ indicate synergism and antagonism, respectively.

A549 and DV90 had synergism at low doses and also in the HOP62 cell line at a broad range of doses of the combinatorial drugs.

The combination results of elisidepsin and gemcitabine in the panel of different cell lines are presented in Table III. In contrast to the previous combinational assays this is the only one with a synergistic effect in all cell lines in at least one of the fixed ratio of doses. All lung carcinoma cell lines have a synergism with gemcitabine at low doses. Moreover, all breast carcinoma cell lines and colon cancer cell line DLD1 have a synergism in a broad range of concentrations, whereas for the other colon carcinoma cell lines, synergism was observed in HT29 only to have synergism in the highest doses tested.

Drug combination using each of these three drugs with elisidepsin has shown more efficacy than the monotherapy alone. Interestingly, the above combination was found to be synergistic even in cell lines less sensitive to elisidepsin, such as HOP62 and MDA-MB-231 cell lines.

\section{Discussion}

Elisidepsin is a novel marine compound with a potent cytotoxic activity in various tumor cell lines. In addition, identical results were obtained in several xenograft studies, supporting the use of this compound in different I and II clinical trials.

The mechanism of action of this compound remain poorly understood, although several targets have been proposed to be involved in the cellular response to elisidepsin treatment, such as fatty acid containing ceramides, FA2H, lysosomes, lipid rafts and epithelial growth factor receptors $(10,12,22,23)$. Although elisidepsin could interact with the lipid bilayer, it is unlikely that it will form pores because the molecule is too small to span the whole length of the lipid bilayer. A minimum of 20 amino acids is required for this action (24) and elisidepsin contains only 14. Recently, ErbB receptors have been proposed as predictive markers of in vitro sensitivity to elisidepsin $(12,13)$

Regarding HER family receptors, in the present study we also observed an association between ErbB3 protein expression and sensitivity to elisidepsin treatment in a variety of cell lines. We observed a relatively rapid (2 and 4 h) specific downregulation of ErbB3 upon elisidepsin treatment in the breast cancer cell line MCF-7, whereas the other ErbB family members were not affected. These data, obtained in a breast cell line model, agree with previous results obtained in a lung cancer model (13), supporting the hypothesis of a selective role of ErbB3 in the cellular response to this drug, although other authors proposed this ErbB role as a secondary process upon cell membrane alterations by elisidepsin treatment (35). 
Table III. In vitro combination of elisidepsin and gemcitabine.

\begin{tabular}{|c|c|c|c|c|c|c|}
\hline Cell line & Origin & $\mathrm{CI}$ (at $0.125 \mathrm{xIC} \mathrm{IC}_{50}$ ) & $\mathrm{CI}$ (at $\left.0.25 \mathrm{xIC} \mathrm{IC}_{50}\right)$ & $\mathrm{CI}$ (at $\left.0.5 \times \mathrm{xIC}_{50}\right)$ & $\mathrm{CI}\left(\right.$ at $\left.1 \mathrm{xIC}_{50}\right)$ & $\mathrm{CI}\left(\right.$ at $\left.2 \mathrm{xIC} \mathrm{C}_{50}\right)$ \\
\hline A549 & Lung & 0.42 & 0.63 & 0.85 & 1.20 & 1.15 \\
\hline DV-90 & Lung & 2.46 & 2.81 & 0.62 & 0.81 & 0.92 \\
\hline HOP-62 & Lung & 1.17 & 0.80 & 0.68 & 1.29 & 1.58 \\
\hline MDA-MB-435 & Breast & 0.17 & 0.24 & 0.43 & 0.78 & 1.17 \\
\hline MDA-MB-231 & Breast & 1.69 & 0.60 & 0.64 & 0.94 & 1.19 \\
\hline MCF-7 & Breast & 9.27 & 1.71 & 1.46 & 0.89 & 0.76 \\
\hline DLD-1 & Colon & 1.59 & 0.57 & 0.62 & 0.90 & 1.17 \\
\hline HT-29 & Colon & 5.06 & 1.60 & 1.32 & 1.12 & 0.91 \\
\hline
\end{tabular}

$\mathrm{CI}$, combination indexes. $\mathrm{CI}<1, \mathrm{CI}=1, \mathrm{CI}>1$ indicate synergism, additive effect and antagonism, respectively.

The lower tyrosine kinase activity of ErbB3 receptor prompts heterodimerization with other HER receptors and ErbB2/ErbB3 heterodimers have been shown to be the most transforming and mitogenic receptor complex of the ErbB family (25-27). These observations suggest that cancer cell lines driven by a member of the ErbB receptor system often couple with ErbB3 to activate the PI3K/Akt pathway, consequently promoting the cancer phenotype $(28,29)$. Akt is a major downstream target of receptor tyrosine kinases that signals via PI3K. Using a broad panel of cell lines including lung, breast, and colon carcinoma, we analyzed the most important pathways downstream of this heterodimer and evaluated the phosphorylation levels of Akt and MAPK in response to elisidepsin treatment. In these cell lines, we observed downregulation of ErbB3 in 6 out of 8 tested cell lines, confirming the previous data in MCF-7, this downregulation being associated with a decrease in the levels of serine 473 phosphorylation in Akt in the same set of cell lines. These results are in agreement with previous results obtained in different cell lines with KF (12), and due to this lower survival signaling, cell lines exhibit a cytotoxic response. Interestingly, the HOP62 cell line shows up-regulation of p-Akt upon elisidepsin treatment, and correlates with a less sensitive phenotype. Taking into account these data, the downregulation of ErbB3 and p-Akt levels could be a good predictive model to detect the in vitro response to elisidepsin.

In contrast, the levels of p-MAPK do not appear to predict cell viability response, because we did not observe significant differences after elisidepsin treatment in resistant (HOP62 and MDA-MB-231) and sensitive (MDA-MB-435 and HT29) cell lines. It is probable that other molecular alterations or crosstalk signaling pathways could activate p-MAPK indirectly, but this phosphorylation does not reflect in vitro elisidepsin sensitivity.

A variety of alterations could be involved in the less sensitive cell line MDA-MB-231, such as the low presence of other possible potential predictive markers of elisidepsin treatment like fatty acid synthase (FAS) (30) or the presence of signaling pathways independent of this drug such as EGFR or Src $(31,32)$.

The mechanisms involved in the downregulation of ErbB3 have been explored previously with KF by other authors with inconclusive results $(5,12,13)$ and therefore still remain unknown. Nevertheless we explored whether basal levels of ErbB3 protein could be a predictor maker to elisidepsin. Importantly we have observed that cell lines with low basal levels of ErbB3 receptor are less sensitive to elisidepsin, whereas in cells with high ErbB3 basal levels there is a correlation with elisidepsin sensitivity, supporting previous indications that ErbB3 could be a good predictive marker of elisidepsin sensitivity; further studies are necessary to confirm this observation in different in vitro and in vivo models.

In order to enhance the cytotoxic effect of elisidepsin and other anticancer drugs, we studied whether the combination of elisidepsin with other current chemotherapeutic agents could be effective in elisidepsin less sensitive cell lines. In this regard, we have tested the cellular effect of elisidepsin combined with CDDP, TAX and gemcitabine. The combination of elisidepsin with CDDP showed synergism in all tested cell lines except for the colorectal cell line HT29. In contrast, the combination of elisidepsin with TAX and gemcitabine showed synergism in all cell lines studied. In our panel of cell lines, the MDA-MB231, MCF-7 and HT29 were the least synergistic with TAX and the HT29 the least synergistic with gemcitabine. HOP62 and MDA-MB-435 were the most synergistic in combination of elisidepsin with TAX and gemcitabine, respectively.

Based on these data, we conclude that the combination of elisidepsin with CDDP, TAX or gemcitabine could be an effective and viable therapeutic option to be evaluated in several in vivo studies and provide a rationale for further development of these combinational treatments in future clinical trials. The combination of elisidepsin with any of the chemotherapeutic agents shows a synergistic effect in different cell lines. The most probably rationale is that elisidepsin treatment could affect cells on the lipidic bilayer membrane, preferentially containing high levels of ErbB3 receptor, and this could enhance the activity of the different tested drugs (CDDP, TAX or gemcitabine). In this regard, tumors that harbor overexpression of ErbB3 could be good candidates to perform this type of combinational studies, such as metastatic breast or lung tumors $(33,34)$.

\section{Acknowledgements}

We would like to thank Stephen Illing for English correction of the manuscript. This study was supported by PharmaMar, Madrid, Spain. 


\section{References}

1. Carter NJ and Keam SJ: Trabectedin: a review of its use in soft tissue sarcoma and ovarian cancer. Drugs 70: 355-376, 2010.

2. Hamann MT, Otto CS, Scheuer PJ and Dunbar DC: Kahalalides: bioactive peptides from a marine mollusk elysia rufescens and its algal diet bryopsis sp.(1). J Org Chem 61: 6594-6600, 1996.

3. Wosikowski K, Schuurhuis D, Johnson K, et al: Identification of epidermal growth factor receptor and c-erbB2 pathway inhibitors by correlation with gene expression patterns. J Natl Cancer Inst 89: 1505-1515, 1997.

4. Gomez SG, Bueren JA, Faircloth GT, Jimeno J and Albella B: In vitro toxicity of three new antitumoral drugs (trabectedin, aplidin, and kahalalide F) on hematopoietic progenitors and stem cells. Exp Hematol 31: 1104-1111, 2003.

5. Suarez Y, Gonzalez L, Cuadrado A, Berciano M, Lafarga M and Munoz A: Kahalalide F, a new marine-derived compound, induces oncosis in human prostate and breast cancer cells. Mol Cancer Ther 2: 863-872, 2003.

6. Yin J, Aviles P, Lee W, et al: Development of a liquid chromatography/tandem mass spectrometry assay for the quantification of PM02734, a novel antineoplastic agent, in dog plasma. Rapid Commun Mass Spectrom 20: 2735-2740, 2006.

7. Rademaker-Lakhai JM, Horenblas S, Meinhardt W, et al: Phase I clinical and pharmacokinetic study of kahalalide $\mathrm{F}$ in patients with advanced androgen refractory prostate cancer. Clin Cancer Res 11: 1854-1862, 2005.

8. Pardo B, Paz-Ares L, Tabernero J, et al: Phase I clinical and pharmacokinetic study of kahalalide $\mathrm{F}$ administered weekly as a 1-hour infusion to patients with advanced solid tumors. Clin Cancer Res 14: 1116-1123, 2008.

9. Chandarlapaty S, Scaltriti M, Angelini P, et al: Inhibitors of HSP90 block p95-HER2 signaling in Trastuzumab-resistant tumors and suppress their growth. Oncogene 29: 325-334, 2010

10. Herrero AB, Astudillo AM, Balboa MA, Cuevas C, Balsinde J and Moreno S: Levels of SCS7/FA2H-mediated fatty acid 2-hydroxylation determine the sensitivity of cells to antitumor PM02734. Cancer Res 68: 9779-9787, 2008.

11. Coussens L, Yang-Feng TL, Liao YC, et al: Tyrosine kinase receptor with extensive homology to EGF receptor shares chromosomal location with neu oncogene. Science 230: 1132-1139, 1985.

12. Janmaat ML, Rodriguez JA, Jimeno J, Kruyt FA and Giaccone G: Kahalalide F induces necrosis-like cell death that involves depletion of ErbB3 and inhibition of Akt signaling. Mol Pharmacol 68: 502-510, 2005.

13. Ling YH, Aracil M, Jimeno J, Perez-Soler R and Zou Y: Molecular pharmacodynamics of PM02734 (elisidepsin) as single agent and in combination with erlotinib; synergistic activity in human non-small cell lung cancer cell lines and xenograft models. Eur J Cancer 45: 1855-1864, 2009.

14. Trimmer EE and Essigmann JM: Cisplatin. Essays Biochem 34: 191-211, 1999.

15. Gonzalez VM, Fuertes MA, Alonso C and Perez JM: Is cisplatininduced cell death always produced by apoptosis? Mol Pharmacol 59: 657-663, 2001.

16. Blagosklonny MV and Fojo T: Molecular effects of paclitaxel: myths and reality (a critical review). Int J Cancer 83: 151-156, 1999.

17. Hortobagyi GN: Recent progress in the clinical development of docetaxel (Taxotere). Semin Oncol 26: 32-36, 1999.
18. Schwartz J: Current combination chemotherapy regimens for metastatic breast cancer. Am J Health Syst Pharm 66: S3-S8, 2009.

19. Raez LE, Kobina S and Santos ES: Oxaliplatin in first-line therapy for advanced non-small cell lung cancer. Clin Lung Cancer 11: 18-24, 2010.

20. Squadroni M and Fazio N: Chemotherapy in pancreatic adenocarcinoma. Eur Rev Med Pharmacol Sci 14: 386-394, 2010.

21. Chou TC and Talalay P: Quantitative analysis of dose-effect relationships: the combined effects of multiple drugs or enzyme inhibitors. Adv Enzyme Regul 22: 27-55, 1984.

22. Shilabin AG, Kasanah N, Wedge DE and Hamann MT: Lysosome and HER3 (ErbB3) selective anticancer agent kahalalide F: semisynthetic modifications and antifungal lead-exploration studies. J Med Chem 50: 4340-4350, 2007.

23. Hama H, Young DA, Radding JA, et al: Requirement of sphingolipid $\alpha$-hydroxylation for fungicidal action of syringomycin $\mathrm{E}$. FEBS Lett 478: 26-28, 2000.

24. Kourie JI and Shorthouse AA: Properties of cytotoxic peptide-formed ion channels. Am J Physiol Cell Physiol 278: C1063-C1087, 2000.

25. Holbro T, Beerli RR, Maurer F, Koziczak M, Barbas CF III and Hynes NE: The ErbB2/ErbB3 heterodimer functions as an oncogenic unit: ErbB2 requires ErbB3 to drive breast tumor cell proliferation. Proc Natl Acad Sci USA 100: 8933-8938, 2003.

26. Alimandi M, Romano A, Curia MC, et al: Cooperative signaling of ErbB3 and ErbB2 in neoplastic transformation and human mammary carcinomas. Oncogene 10: 1813-1821, 1995.

27. Wallasch C, Weiss FU, Niederfellner G, Jallal B, Issing W and Ullrich A: Heregulin-dependent regulation of HER $2 /$ neu oncogenic signaling by heterodimerization with HER3. EMBO J 14: 4267-4275, 1995.

28. Prigent SA and Gullick WJ: Identification of c-erbB-3 binding sites for phosphatidylinositol 3'-kinase and SHC using an EGF receptor/c-erbB-3 chimera. EMBO J 13: 2831-2841, 1994.

29. Burgering BM and Coffer PJ: Protein kinase B (c-Akt) in phosphatidylinositol-3-OH kinase signal transduction. Nature 376: 599-602, 1995.

30. Menendez JA, Mehmi I, Atlas E, Colomer R and Lupu R: Novel signaling molecules implicated in tumor-associated fatty acid synthase-dependent breast cancer cell proliferation and survival: Role of exogenous dietary fatty acids, p53-p21WAF1/CIP1, ERK1/2 MAPK, p27KIP1, BRCA1, and NF-кB. Int J Oncol 24: 591-608, 2004.

31. Hirsch DS, Shen Y and Wu WJ: Growth and motility inhibition of breast cancer cells by epidermal growth factor receptor degradation is correlated with inactivation of Cdc42. Cancer Res 66: 3523-3530, 2006.

32. Biscardi JS, Belsches AP and Parsons SJ: Characterization of human epidermal growth factor receptor and c-Src interactions in human breast tumor cells. Mol Carcinog 21: 261-272, 1998.

33. Xue C, Liang F, Mahmood R, et al: ErbB3-dependent motility and intravasation in breast cancer metastasis. Cancer Res 66: 1418-1426, 2006

34. Sun M, Behrens C, Feng L, et al: HER family receptor abnormalities in lung cancer brain metastases and corresponding primary tumors. Clin Cancer Res 15: 4829-4837, 2009.

35. Váradi T, Roszik J, Lisboa D, et al: ErbB protein modifications are secondary to severe cell membrane alterations induced by elisidepsin treatment. Eur J Pharmacol 667: 91-99, 2011. 